\title{
Da democracia participativa à desdemocratização na cidade: a experiência do Orçamento Participativo em Porto Alegre
}

\author{
From participatory democracy to de-democratization in the city: \\ the experience of Participatory Budgeting in Porto Alegre
}

Lucimar Fátima Siqueira [I] Eber Pires Marzulo [II

\begin{abstract}
Resumo
Neste artigo se analisa o efeito da democracia na produção da cidade, tendo como caso a particular experiência de Porto Alegre pós-Constituição de 1988. Analisa-se a relação Estado-sociedade civil através das instituições participativas estabelecidas. A análise foca na experiência do Orçamento Participativo (OP), e tem-se, como método, a análise de discurso de documentos oficiais, legislação, atas; e a etnografia política, a partir da observação em rodada de assembleias do OP e do Conselho do OP. Estabelece-se um quadro da experiência democrática, a saber: 1) democracia-participativa (1989-2004); 2) liberal-governança (2005-2016); e 3) ultraliberal-mercado (2016-). Distintas formas de democracia que incidem nas dinâmicas de produção da cidade.
\end{abstract}

Palavras-chave: democracia; cidade; Porto Alegre; democracia participativa; desdemocratização.

\begin{abstract}
This article analyzes the effect of democracy on the city's production, taking into account the particular experience of Porto Alegre after the 1988 Brazilian Constitution. The state-civil society relationship is analyzed through established participatory institutions. The analysis focuses on the experience of participatory budgeting (PB) and the method is the discourse analysis of official documents, legislation and minutes, and political ethnography, through the observation of $P B$ assemblies and Council. A framework of the democratic experience is established, namely: 1) participatory democracy (1989-2004); 2) liberal governance (2005-2016); 3) and ultraliberal market (2016-), representing the different forms of democracy that affect the production dynamics of the city.
\end{abstract}

Keywords: democracy; city; Porto Alegre; participatory democracy; de-democratization. 


\section{Introdução}

Uma das lutas que se trava na sociedade urbana contemporânea é entre o tempos da cidade e o tempo da democracia. O tempo da democracia é longo. São longos os períodos da história e da sociedade para que algum aspecto da democracia se modifique. Já os tempos da cidade são múltiplos e complexos, sobretudo quando se trata da reprodução do capital em que a temporalidade se torna estrutural, relacionada aos ciclos do modo de produção (Jameson, 2011), por um lado e, por outro, das necessidades da população pobre, do tempo existencial, do tempo da vida cotidiana. Com Jameson (ibid.) podemos tomar o verbo "extinguir" para imaginarmos a temporalidade na cidade. "Desse verbo vem passado e futuro, juntamente com uma visão de presente como produção [...]" (ibid., p. 93). Cada avenida inaugurada em local já habitado surge reificada, sem qualquer vestígio de sua produção ou das casas destruídas para que delas emergisse uma cidade. Se o tempo do capital na cidade é diferente do tempo da democracia, é preciso estabelecer garantias para o cidadão. Isto se dá através da operacionalização de direitos conquistados e conjunto de regras estabelecidas, pois os tempos da democracia no cotidiano são assinalados através de mecanismos presentes nas administrações públicas de governos democráticos.

No Brasil pós-Constituição de 1988, a gestão democrática da cidade, gestada no âmbito das lutas pela reforma urbana ainda na década de 1960 e consolidada no Estatuto da Cidade (Saule, Jr. e Uzzo, 2009), promove a ampliação dos espaços de participação nas cidades e/ou reestruturação, no caso daqueles já existentes. A esse respeito, é importante lembrar que já existiam no Brasil espaços de participação como os conselhos, porém não havia o princípio da participação popular. Esse processo possibilitado pela Constituição de 1988 permite a abertura direta da gestão urbana aos movimentos sociais e demais entidades da sociedade civil. Estabelece-se assim, oficialmente, a gestão democrática da cidade "como meio de participação da população e de associações representativas dos vários segmentos da comunidade na formulação, execução e acompanhamento de planos, programas e projetos de desenvolvimento urbano" (Brasil, 2001). Um arcabouço jurídico instala-se, oferecendo legitimidade para a "construção de novos arranjos institucionais de interação entre governo e sociedade, para além das instituições clássicas da democracia liberal" (Santos Júnior, Nascimento e Ferreira, 2007, p. 2).

Com o intuito de implementar a política urbana presente na Constituição Federal, governos e sociedade trataram de construir um conjunto de espaços e ações em todos os níveis do Estado. 0 estabelecimento do Estatuto da Cidade, em 2001, define especificamente os instrumentos que deverão garantir a gestão democrática da cidade, a saber: órgãos colegiados de política urbana nos níveis nacional, estadual e municipal; debates, audiências e consultas públicas; conferências nos três níveis; e iniciativa popular de projeto de lei e planos, programas e projetos de desenvolvimento urbano (Brasil, 2001). A partir do início do governo Lula (20032006; 2007-2010), em 2003, e à luz do Estatuto da Cidade, a criação dos conselhos municipais e a realização das conferências produziram um ambiente para a participação da sociedade nas discussões sobre os rumos das cidades brasileiras. A cidade assumia centralidade no projeto nacional traduzida pelas mudanças 
institucionais ocorridas no período, como a criação do Ministério das Cidades (2003), a aprovação do Estatuto da Cidade (2001), a realização da primeira Conferência Nacional das Cidades (2003), e pela atuação dos movimentos sociais, “[...] poucas vezes, no passado recente, criaram-se condições tão favoráveis para uma discussão sistemática e aprofundada das causas de nossa miséria e desigualdade urbanas e, evidentemente, dos caminhos para superá-las" (Vainer, 2005). Entre esses caminhos, estavam os mecanismos e as instâncias de participação da gestão democrática da cidade.

Três outros acontecimentos anteriores à Constituição de 1988 colaboraram com a articulação propiciada pela abertura democrática em torno da questão urbana. Trata-se da publicação do Anteprojeto de Lei Federal de Desenvolvimento Urbano, em 1982, do documento da Confederação dos Bispos do Brasil - Solo Urbano e Ação Pastoral (1982) e, em 1986, o debate sobre Serviço Federal de Habitação, coordenado pelo Instituto dos Arquitetos do Brasil. Ações que sintetizaram os debates anteriores do período de transição da ditadura militar à democracia, impulsionando a organização e articulação de entidades e movimentos populares em torno da agenda urbana que se vislumbrava. 0 período de treze anos transcorrido entre a publicação da Constituição Federal de 1988 e a aprovação do Estatuto (2001) pode ser curto, se considerarmos os tempos da democracia, mas foi longo levando-se em conta a necessidade e as dinâmicas de segregação e exclusão socioespacial das cidades brasileiras. Ambos os instrumentos instituídos com potencial para instrumentalizar o enfrentamento ds desigualdades socioespaciais, portanto de implementação urgente. Esse interstício temporal não apenas demonstra que uma parte da sociedade não estava pronta para acolher os valores que sustentavam o conteúdo que se pretendia incluir no Estatuto da Cidade, mas também que havia forças contrárias muito fortes. Ao mesmo tempo que os movimentos sociais encontravam espaço para propor e debater a política urbana, setores ligados ao mercado imobiliário e construção civil também participavam do mesmo fórum. Foi um período de constantes disputas e embates entre os distintos atores interessados na pauta da política urbana.

A criação do Ministério das Cidades (2003), do Conselho Nacional das Cidades, eleito por ocasião da primeira Conferência das Cidades no ano de 2003 e constituído como espaço de debates, recomendações e contribuição para a implementação das deliberações da 1a , 2ª , 3a , 4a e 5á Conferências (2003, 2005, 2007, 2009-2010, 2013) e da Política Nacional de Desenvolvimento Urbano; o ciclo de elaboração de planos diretores, que incluíram o adjetivo participativo; o Sistema Nacional de Habitação de Interesse Social; e a política de regularização fundiária, podem ser considerados as principais conquistas da sociedade relacionadas à política urbana brasileira pós-Constituição de 1988. Todavia, no período pós-Estatuto da Cidade (2001), as intervenções e os programas destinados às cidades estiveram muito mais voltados para grandes programas, como o Plano de Aceleração do Crescimento (PAC) e o Programa Minha Casa Minha Vida (PMCMV), e poucos avanços trouxeram na implantação de instrumentos que pudessem regular a função social da propriedade, questão arduamente defendida pelos movimentos sociais e cujo não estabelecimento era denunciado pelas ocupações urbanas, entre outros atos de protesto (Santos Júnior, Nascimento e Ferreira, 2007). 
Importante tratar do impacto do golpe de 2016 sobre a política urbana, pois imediatamente após o golpe, em abril, ocorre a desconstrução de espaços de centrais na participação popular, como o Conselho Nacional das Cidades. A interrupção da realização da 6 a Conferência Nacional das Cidades e a retirada do Conselho Nacional das Cidades como organizador da Conferência, através do decreto n. 9.076, de 7 de junho de 2017; ${ }^{1}$ a suspensão temporária do programa PMCMV - Entidades (modalidade do programa diretamente relacionada aos movimentos sociais) pela portaria ministerial n. 186 de 13 de maio de 2016, com o argumento de readequação orçamentária, e seu retorno com modificações substanciais que dificultavam o trabalho dos movimentos populares envolvidos; a publicação da lei n. 13.465/2017, conhecida como "Lei da Grilagem", cuja discussão ocorreu ao longo de 2017 com a insígnia de MP 759; foram medidas que atingiram diretamente as conquistas das lutas urbanas e mecanismos de democracia participativa na gestão da cidade. A lei n. 13.465/2017 merece destaque, na medida em que desnuda o sentido do governo Temer (2016-2018) no tratamento da questão urbana. A lei possibilita a disponibilização de terra no mercado de forma mais facilitada às grandes corporações nacionais e estrangeiras, além de facilitar a regularização fundiária de mercado, ou seja, apenas pela titulação (sem urbanização). Coloca-se em lei aquilo que até então era considerado uma denúncia: "a acumulação por despossessão" (Harvey, 2004).

A acumulação por despossessão funciona como mecanismo facilitador de regularização fundiária sem urbanização, possibilitando a aquisição de pequenas frações de terreno que se encontram em posse de moradores de áreas carentes por investidores ou empreendedores imobiliários, ao contrário do previsto pelo Estatuto da Cidade, em que a regularização fundiária exige urbanização. Ao adquirirem essas terras contíguas, regularizadas e a baixíssimo custo, pois não urbanizadas, investidores e empreendedores imobiliários podem as incorporar e realizar empreendimentos imobiliários, promovendo, assim, a acumulação por despossessão. Ou seja, a lei tem sentido oposto ao Estatuto da Cidade, em que se valoriza a posse para possibilitar a urbanização. Conforme Fernandes (2011), essa forma de regularização fundiária foi bastante utilizada no Peru a partir da proposta do economista Hernando de Soto, especialmente durante o governo Alberto Fujimori (1990-1992). A regularização em escala com o objetivo do desenvolvimento urbano acelera a acumulação e concentração da propriedade fundiária, ao considerar apenas as unidades fundiárias e não levando em conta contexto social, infraestrutura e urbanização (ibid.). No Brasil, o Estatuto da Cidade prevê a regularização fundiária associada à regularização urbanística, com a integração da moradia ao restante da cidade. Aspecto que se perde nos casos em que a lei n. 13.465/2017 for implantada.

Se a Constituição de 1988 é um marco na história da democracia do País, por apresentar as condições jurídicas necessárias à abertura de espaços para participação popular nas estruturas do Estado, caracterizando-se pelo estabelecimento da democracia representativa associada à democracia participativa, sua incidência na cidade apenas estará disponível a partir da implantação do Estatuto da Cidade em 2001. No entanto, cabe salientar que formas de democracia participativa já 
estavam em curso no Brasil nesse interstício entre a promulgação da Constituição e o Estatuto da Cidade. 0 caso mais emblemático foi a experiência do Orçamento Participativo (OP) em Porto Alegre, a partir de 1989, que sofre, desde 2005, processos regressivos no que diz respeito à democracia participativa, cujo ápice de regressão foi o estabelecimento, pelo governo municipal (2017-2020), em 2017, da suspensão das decisões do OP. Assim como no País, os avanços democráticos na gestão urbana no nível das cidades também estão envolvidos em processo regressivo das experiências democráticas.

A abordagem proposta por Avritzer (2018), ao analisar a democracia a partir de resultados eleitorais contestados, entende que a contestação é o resultado da vontade do povo e sugere que o entendimento dos fatos e das mudanças contemporâneas necessita de uma análise mais distante no tempo, para fundamentar a ideia de uma "visão pendular" da experiência democrática brasileira, ou seja, se hoje a democracia brasileira não vai bem, devemos "perceber que, em determinados momentos históricos, elites e massas no Brasil partilharam um forte entusiasmo democrático que propicia medidas na direção da ampliação da soberania popular e dos direitos" (ibid., p. 275). Os movimentos pendulares regressivos da democracia estariam associados a "fortes divisões políticas, crise econômica e profundo desacordo em relação ao projeto de país." (ibid.). Os processos de regressão ou retrocessos da democracia, são definidos por Tilly (2013) como "desdemocratização", cuja análise teria como núcleo as respostas dos governos às demandas da população. A experiência de democracia participativa, através do OP em Porto Alegre, estaria em sintonia com as transformações e os avanços estabelecidos pela Constituição de 1988, em termos da democracia representativa e de seu esvaziamento explicitado com o cancelamento do atendimento de demandas no mesmo movimento pendular da democracia representativa, a partir do golpe parlamentar de 2016 e da vitória eleitoral de programa antidemocrático de direita em 2018.

\section{Democracia e desdemocratização}

A democracia moderna apresenta, em sua base constitutiva, dois princípios: a liberdade e a igualdade. As sociedades democráticas vão se diferenciar em função da forma como tratarão esses dois princípios. Sociedades liberais, por exemplo, darão mais peso à liberdade do ponto de vista econômico em detrimento da igualdade, como superação de discriminação. 0 princípio da igualdade tem como origem a ideia de indivíduos iguais à luz dos valores ligados ao pensamento cristão relacionado à "doutrina da natureza humana comum" (Bobbio, 2000, p. 378). No entanto, a democracia clássica grega não contemplava a igualdade, sendo apenas a partir da influência dos filósofos do iluminismo (século XVIII) que a questão da igualdade como superação da discriminação passa a ser incorporada nos debates relacionados à democracia. Em relação ao conceito de liberdade, este pode ser interpretado como a liberdade individual ou a liberdade negativa, isto é, a liberdade ante o Estado ou a outros, que se desenrola onde não há impedimentos e cujos indivíduos livres podem concorrer entre si como agentes econômicos; 
ou a liberdade dos indivíduos na formação da vontade coletiva, considerada liberdade positiva, ou seja, derivada da associação política entre indivíduos que coletivamente instauram um acordo societário. Segundo Bobbio (1994), o "nexo recíproco entre liberalismo e democracia é possível porque ambos têm um ponto de partida comum: o indivíduo. Ambos repousam sobre uma concepção individualista da sociedade" (p. 45).

Mouffe (1999), no entanto, aponta que não poderia existir perfeita igualdade entre liberalismo e democracia, pois o liberalismo está associado ao princípio de liberdade, e democracia ao princípio de igualdade. A tensão entre os dois princípios será permanente, e a democracia permite, por princípio, a abertura ou a possibilidade de luta entre os dois princípios que precisam ser distinguidos no interior da modernidade política estruturada entre a política liberal e a política democrática. Nesse sentido, tem-se a constituição do dissenso, desde a crítica à teoria política dominante fundada no consenso, pois esta não consegue "captar as diferentes formas de antagonismos que emergem em nosso mundo globalizado, pós-guerra fria, e enfrentar um tipo de política democrática que poderia dar conta deles" (Mouffe, 2003, p. 11)). E a consequente radicalização da democracia, cujo ponto fundamental está na necessidade de aprofundar e "conectar as distintas lutas democráticas" (Mouffe, 1999, p. 39). Para isso, será necessário se constituir "novas posições subjetivas que permitam a articulação comum de, por exemplo, antirracismo, antisexismo, anticapitalismo" (ibid.). Assim, a democracia radical exige que se reconheça a diferença, aquilo que o conceito abstrato de homem excluía, e o sentido consensual de democracia impede.
Não se trata de rechaçar o universalismo, mas de o constituir a partir do particular e, logo, do dissenso.

Rancière (1996) também compartilha da crítica ao consenso, sobretudo "a crítica do discurso atualmente dominante que identifica a racionalidade política ao consenso e o consenso ao princípio mesmo da democracia" (p. 367). Afinal, em muitos casos, a democracia foi conquistada através de eleições impostas e com uso de forças armadas que estabeleciam formas de democracia que se opunham à democracia do povo, pois esta remete ao sentido primeiro da democracia que é o de "governo do povo, por ele mesmo e não trazido de fora pela força das armas" (Rancière, 2014, p. 13). Por um lado, os idealistas defendem uma expansão das atividades democráticas e alimentam a vitalidade da democracia; por outro, os agentes econômicos defendem o controle dessa situação. Assim, se, para os defensores da vitalidade democrática, a liberdade pode levar à pluralidade de demandas no contexto de ampliação democrática, enquanto democracia radical; a democracia liberal necessita controlar, ou seja, impor limites a essa liberdade democrática através da canalização da vitalidade societária para a liberdade do consumo. A democracia liberal contemporânea, ao valorizar o individualismo, através do fortalecimento da liberdade individual, amplia o consumo (ibid.). Portanto, a democracia não é algo acabado, que se resume a instituições, governos, partidos, mas é algo dinâmico e que origina do povo, sobretudo pelo direito a uma vida política independente da esfera estatal. É "a busca pela consciência de viver junto" (ibid., p. 94).

Nesse jogo de tensões contraditórias, visualizam-se as divergências entre democracia como forma de governo e democracia 
como poder do povo, estabelecendo-se o distanciamento entre os interesses dos governos (democracia representativa) e o poder do povo (democracia participativa e/ou direta). Tais interesses díspares entre governo e população tendem a disparar um processo de desdemocratização. Então, tem-se um gradiente da democracia, de mais a menos democrático, cujos polos são a $\operatorname{maxD}$, a máxima democracia, e a minD, a mínima democracia (Menser, 2005). A maxD apresenta uma concepção política participativa, orientada por objetivos relacionados aos direitos humanos e à justiça social e pode ser desenvolvida sob distintas formas, seja através de procedimentos não representativos ou de misturas de mecanismos participativos e representativos, com interface com Estado e com a institucionalização burocrática.

A democracia máxima considera todo o plano econômico e sociocultural como um campo apropriado para os desejos e práticas democráticos. Como tal, a organização da vida cotidiana nas escolas, na recreação, na casa, no local de trabalho, na religião e na unidade familiar não são esferas distintas a serem protegidas por sujeitos adequados para a transformação. Essa democratização da sociedade requer a (re)construção de um conjunto de instituições políticas e econômicas que promova as capacidades e os conhecimentos requeridos para o autogoverno. Novamente, o maxD não é uma questão de soletrar os direitos individuais. Trata-se, sim, da produção de um conjunto de capacidades coletivas. (pp. 93-94; tradução livre) ${ }^{2}$

Ademais, a mínima democracia seria aquela do governo como representação, em que a cidadania tem o direito de ter seus interesses registrados por quem exerce poder executivo, legislativo, jurídico e administrativo. Geralmente ocorre por mecanismos eleitorais em que cidadãos têm direito de concorrer a cargos, independentemente de classe, gênero ou religião (ibid.), marcada pela "concepção de governança neoliberal globalmente predominante que se distingue pela sua fidelidade à distinção público/privado a serviço do capitalismo global" (ibid., p. 90). O poder cooperativo presente na democracia participativa lhe é intrínseco, sobretudo em relação à capacidade de reduzir desigualdades. Dessa forma o foco da democracia participativa está no poder e na igualdade no campo da prática das instituições. Sintomer, Herzberg e Röcke (2012) definem que "esse modelo implica a participação da classe trabalhadora ou dos grupos vulnerabilizados e não apenas das classes médias, bem como o surgimento de uma esfera pública "plebeia'" (p. 100).

\section{Democracia e cidade: o caso de Porto Alegre}

O estabelecimento formal de esferas públicas de interação entre governo e sociedade em Porto Alegre remonta ao ano de 1892, quando a Lei Orgânica Municipal (LOM) registrou a presença de conselho municipal criado pelo intendente Alfredo Augusto de Azevedo (1892-1896) (Gomes, 2011). Esse formato de conselho, porém, foi uma instituição herdada do período anterior, as câmaras, que se tratava de prolongamento administrativo da estrutura portuguesa (Sanhudo, 1961). Com as mudanças ocorridas no País, a partir da década de 1930, sobretudo com o ato de Getúlio Vargas que dissolveu o Congresso e os legislativos 
estaduais e municipais, Porto Alegre sofre reflexo e, nela, ocorre a extinção do conselho municipal (ibid.). Somente no ano de 1937, no governo de José Loureiro da Silva (1937-1943), a figura dos conselhos retorna à administração do município com a criação do Conselho Técnico da Administração (1937) e o Conselho do Plano Diretor (1939). O primeiro sendo resultado das intenções de modernização administrativa do governo de Loureiro da Silva. Por sua vez, o Conselho do Plano Diretor veio no contexto da elaboração do Plano Diretor com a contratação de Arnaldo Gladosh, cujo plano foi denominado Plano Gladosh.

Ao longo de sua história, Porto Alegre criou outras esferas de interação entre governo e sociedade, experimentando diferentes perspectivas e formas de atuação, como os conselhos populares, comunitários, de notáveis (Naha, 2005). Dos conselhos de notáveis (Porto Alegre, 2018) que opinavam sobre os rumos da cidade nas primeiras composições do Conselho do Plano Diretor, aos conselhos com recorte popular, cujas discussões levaram ao projeto dos Conselhos Populares (19861987). Embora tais esferas ganhassem visibilidade nos debates que ocorreram na década de 1980 e fossem qualificadas como espaços de participação popular, é através da implantação do OP, em 1989, que a experiência da ampla participação das classes populares nos espaços de interação entre governo e sociedade ganha fôlego e relevância em Porto Alegre. A partir da redemocratização do Brasil, identificam-se três períodos distintos de experiência da democracia. O período entre 1989 e 2004, da Administração Popular, quando o Partido dos Trabalhadores esteve no poder. De 2005 até 2016, cuja principal marca da gestão é Governança Solidária Local (GSL) sob os partidos
PPS, PMDB, PDT. E, na atualidade, uma gestão caracterizada pela alcunha de "Nossa cidade quer mudanças", sob o partido PSDB (20172020). Cada um desses períodos apresentou formas distintas de tratar da questão da democracia participativa.

Ao longo de 29 anos (1989-2017) de existência do $O P$, cada gestão deixou sua marca na democracia participativa de Porto Alegre. Mesmo no período em que o Partido dos Trabalhadores (PT) esteve no poder (1989-2004), as distintas tendências do partido, Democracia Socialista (DS), Articulação de Esquerda (Articulação) e PT Amplo e Democrático (Amplo), apresentavam visões internas particulares, bem como estabeleciam coalizões específicas e que refletiam sobre a forma de conduzir a democracia participativa em Porto Alegre. Além dos diferentes projetos das principais correntes internas do PT em relação ao OP e outras formas de democracia participativa, outros fatores compuseram um quadro em que possibilidades, oportunidades, vontade política e um corpo social engajado orientaram resultados da experiência. "Desde a análise da trajetória de uma organização e da modulação dos arranjos institucionais, também importa analisar os eventos que podem reorientar (momentos, timing) o curso das articulações e dos arranjos internos" (Filomena, 2015, p. 20). Além do OP, durante os 16 anos de governo do PT na cidade, tem-se uma série de eventos que reforçam a experiência de democracia participativa e de seu alcance. Da gestão de Olívio Dutra (19891992) até a gestão Genro-Verle (2001-2004), ocorreu a rediscussão, reestruturação e criação de novos conselhos, cujo resultado foi a instalação de 25 conselhos de políticas públicas durante a totalidade dos governos da Administração Popular (1989-2004). ${ }^{3}$ Interessa 
tratar em especial dos eventos que incidiram na reflexão e alargamento da experiência de democracia participativa desde o OP. São eles: a realização do Projeto Porto Alegre Mais - Cidade Constituinte, instaurado a partir de 1993, e o I Congresso da Cidade e Conferência da Cidade (1993), ambos no primeiro governo de Tarso Genro (1993-1997); o Seminário Internacional de Democracia Participativa (1999) e a atualização do Plano Diretor (1999) no governo de Raul Pont (1997 à 2000); e a realização do Fórum Social Mundial (2001; 2002; 2003), no governo Genro-Verle (2001-2004).

\section{A experiência radical do Orçamento Participativo}

Quando a Frente Popular chegou ao poder, em 1989, já havia a presença de uma vibrante mobilização popular, comunitária, exercida pelos movimentos populares, sobretudo organizados para resistir às remoções, na época conhecidas como despejos. A tentativa de organização de conselhos populares nos anos de 1986 e 1987 (governo Colares) contribuiu para criar um ambiente de mobilização popular imprescindível para o funcionamento do futuro OP. No Quadro 1, tem-se a cronologia da mobilização popular, com seus principais marcos, considerados pelos movimentos populares, que precederam a primeira plenária do OP.

A plataforma defendida pela Frente Popular (1989-1992) foi caracterizada pela democratização das relações entre Estado e sociedade civil. No primeiro ano (1989), a administração foi marcada pela falta de recursos, discussão pública do orçamento, definição de 16 regiões da cidade com lideranças comunitárias, promoção da reforma tributária e a primeira reunião do OP na Zona Norte de Porto Alegre. Pont (2000) cita três características emblemáticas do Orçamento Participativo:

a) a participação popular: não só no orçamento participativo, como na rede de conseIhos municipais formados por representantes de entidades e associações que influenciavam, também, as políticas públicas;

b) a prática direta: ação dos cidadãos nas reuniões, nas discussões e momentos de conhecimento dos dados, dos números;

c) a auto-organização: expressa na autorregulamentação construída e decidida pelos próprios participantes. (pp. 20-21)

Segundo Genro (1997), o OP visava democratizar também as decisões e informações sobre as questões públicas, incidindo na formação política da cidadania. O OP apresenta uma construção coletiva, estruturada pelo governo municipal e pela sociedade civil, cujas demandas têm origem nas regiões e nas temáticas do próprio OP. A sociedade civil organiza-se a partir de uma base territorial, primeiro em 16 regiões e, depois, em 17 (Regiões do Orçamento Participativo - ROP). A dinâmica em cada região se dá através dos Fóruns Regionais do OP (Frop), criado em 1991, nos quais conselheiros e delegados animam as discussões com as comunidades. A relação direta com 0 poder público ocorre através do espaço de participação denominado Conselho do Orçamento Participativo (COP), do qual somente conselheiros e suplentes participam, representando a sociedade, no caso as regiões do OP e temáticas, e representantes do governo municipal. 0 governo detém a coordenação/ gestão institucional, através da coordenação política, responsável pelo processo do OP e apoio nas regiões, e técnica, com equipe que 
Quadro 1 - Cronologia dos marcos até o OP - 1970-1990

\begin{tabular}{|c|l|}
\hline Ano/Período & \multicolumn{1}{|c|}{ Marcos } \\
\hline $\begin{array}{c}\text { Fim dos anos 1970 } \\
\text { e início de 1989 }\end{array}$ & $\begin{array}{l}\text { Os despejos que ameaçam muitas vilas em Porto Alegre levam ao fortalecimento de um } \\
\text { movimento popular que luta por moradia e infraestrutura básica. Associações de moradores } \\
\text { se multiplicam, reunidas sob a bandeira da Federação Riograndense das Associações dos } \\
\text { Amigos dos Bairros (Fracab). }\end{array}$ \\
\hline 1983 & $\begin{array}{l}\text { Fundação da União das Associações de Moradores de Porto Alegre (Uampa), com o objetivo } \\
\text { de articular as lutas do movimento popular. }\end{array}$ \\
\hline 1986 & Surgimento da proposta de criação e papel dos conselhos populares. \\
\hline $1988 / 1989$ & $\begin{array}{l}\text { Vitória da Frente Popular nas eleições municipais. Olívio Dutra entra na prefeitura e chama } \\
\text { os movimentos sociais. Primeira reunião do OP. }\end{array}$ \\
\hline 1990 & $\begin{array}{l}\text { Primeira assembleia plenária do OP com movimento social e início das discussões do orça- } \\
\text { mento municipal. As comunidades de base, pela via das associações e conselhos populares, } \\
\text { debatem as prioridades. }\end{array}$ \\
\hline
\end{tabular}

Fonte: adaptado de: ONG Solidariedade (2003, p. 36).

trata dos aspectos técnicos do orçamento. A coordenação política esteve organizada pela implantação de Centros Administrativos em cada ROP. Inicialmente, chamavam-se Centros Administrativos Regionais (CAR) e depois passaram a ser Centros de Relação Institucional Participativa (Crip). Apesar de as comunidades expressarem sua vontade de escolher os representantes nos centros administrativos, esta foi uma decisão do governo. Assim, o governo tem os coordenadores, gestores locais nos centros administrativos de todas as regiões, e a coordenação realizada por uma secretaria composta por secretário, secretário adjunto e gerente de democracia participativa. Além das regiões, o OP estruturou-se por discussões temáticas, através de 6 Plenárias Temáticas: 1) Circulação, Transporte e Mobilidade Urbana; 2) Cultura; 3) Desenvolvimento Econômico, Tributação, Turismo e Trabalho; 4) Educação,
Esporte e Lazer; 5) Habitação, Organização da Cidade, Desenvolvimento Urbano e Ambiental; 6) Saúde e Assistência Social. Quando foram criadas, as plenárias temáticas visavam a atender demandas que implicavam mais de uma das regiões. Isto possibilitava, aos conselheiros, conhecer e discutir problemas de toda a cidade e sobre "dimensões mais gerais da vida da cidade, comuns a todas as regiões" (Nuñez, 2010, p. 73). Depois, as temáticas envolveram também discussões sobre serviços, diretrizes e investimentos para toda a cidade sob a forma de "obras estruturais e grandes projetos".

O processo completo do OP ocorre através do chamado Ciclo do OP, quando, ao longo do ano, tem-se cronograma definido com pautas, ações, plenárias e assembleias. 0 resultado material das discussões sobre o orçamento se traduz, para a população, através das demandas realizadas. As demandas são definidas 
coletivamente, gravadas no Plano de Investimentos (PI) para discussão com as secretarias e a coordenação técnica do OP. Somente após essa etapa, as demandas poderão compor a Lei Orçamentária Anual do município a ser encaminhada à Câmara Municipal. Não significa, com isto, que serão realizadas. Nesse sentido, as demandas assumem um papel central. "Mais uma obra da participação popular" é uma frase escrita em placas que sinalizam uma conquista do OP. "É conquista do OP", também dizem os moradores, quando perguntados sobre determinado equipamento público nas comunidades. As regiões com "alta concentração de núcleos de subabitação e com níveis maiores de organização e mobilização social, verificados a partir do final dos anos 1970 e início dos anos 1980, foram as escolhidas para a alocação prioritária dos investimentos em 1991" (Fedozzi, 2000, p. 35). Ou seja, o governo respondia às demandas da população. Durante a primeira gestão da Administração Popular-AP (1989-1992), as principais demandas implementadas tratavam de melhorias nas condições de moradia e urbanização do entorno, produção habitacional, saneamento básico, melhorias nas condições de transporte e vias de acesso às comunidades, implementação de equipamentos de saúde, de esporte e lazer (campo de futebol - os "campinhos" -, cancha de bocha, churrasqueiras públicas), serviços, reforma do Mercado Público de Porto Alegre e projetos culturais. Essas demandas foram realizadas em todas as Regiões do Orçamento Participativo - ROP (Porto Alegre, 2018). A Figura 1 mostra a distribuição das demandas concluídas por regiões, serviços e valores, ${ }^{5}$ na primeira gestão da Administração Popular.

Pode-se observar, na Figura 1, que no período 1989-1992 houve uma concentração de investimentos nas regiões Centro, área mais densa que inclui os bairros centrais e pericentrais; Norte, também com densidade alta e bastante consolidada; e Leste, região de expansão histórica e com grandes concentrações de caráter popular. Em termos dos investimentos por serviços demandados, encontra-se uma alta concentração em Educação, e muito abaixo em Saúde. Ao se tomar as regiões com mais investimentos, tem-se a característica de áreas da cidade com maior tradição de organização política e acesso a infraestrutura urbana.

Figura 1 - Demandas concluídas e investimentos na gestão 1989-1992
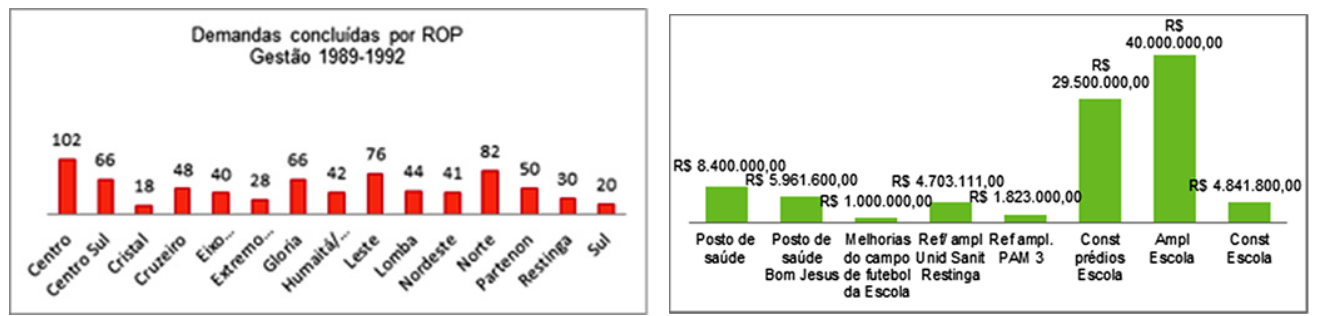

Fonte: Gerência de Democracia Participativa Local - Prefeitura Municipal de Porto, em 2018. 
De certa forma, aspectos que marcam as análises sobre o OP no sentido de uma tendência à concentração em áreas pericentrais e, logo, maior concentração populacional e capacidade política. Certamente essas condições permitem entender o motivo pelo qual os investimentos em infraestrutura urbana não foram tão demandados.

No interstício entre 1993-1996 (Figura 2), segundo governo de funcionamento do OP, a região Centro segue entre as regiões com a maior conclusão de demandas, mas pouco abaixo das regiões Humaitá-Navegantes e Leste. Todavia, em termos de volume de investimentos, ocorre a concentração na região Leste e Lomba do Pinheiro. Ou seja, em relação ao período 1989-1992, surgem com relevância as regiões Humaitá e Lomba do Pinheiro e permanecem entre as com maior número de demandas concluídas e valores investidos a Centro e Leste. As regiões Humaitá-Navegantes e Lomba do Pinheiro estão situadas em áreas opostas à cidade, mas ambas com características populares e classicamente com problemas de infraestrutura. A região Norte segue com número significativo de demandas atendidas e investimentos, mas atrás das demais.

As regiões Eixo-Baltazar e Glória (Figura 3) aparecem com alto número de demandas concluídas no período relativo ao terceiro governo de OP (1997-2000), em seguida estão as regiões Sul, Partenon e Cruzeiro, todas essas áreas da cidade historicamente com graves problemas de infraestrutura e acesso a serviços urbanos, grandes contingentes populacionais de baixa renda, com grandes favelas, e tradição de organização popular. Tais transformações sugerem que a experiência de atendimento das demandas nas regiões mais centrais se alastra, e o OP consolida-se em um movimento para a periferia da cidade. Sinalização que já havia começado no período anterior com a emergência das regiões Humaitá-Navegantes e Lomba do Pinheiro. A observação da Figura 3 traz uma desproporção do investimento na região Humaitá-Navegantes e apresenta um novo aspecto dos investimentos pelo OP: obras de caráter estrutural com impacto na cidade e aumento da capacidade de investimento (Marzulo e Marx, 2013).

Figura 2 - Demandas concluídas e investimentos na gestão 1993-1996 - AP
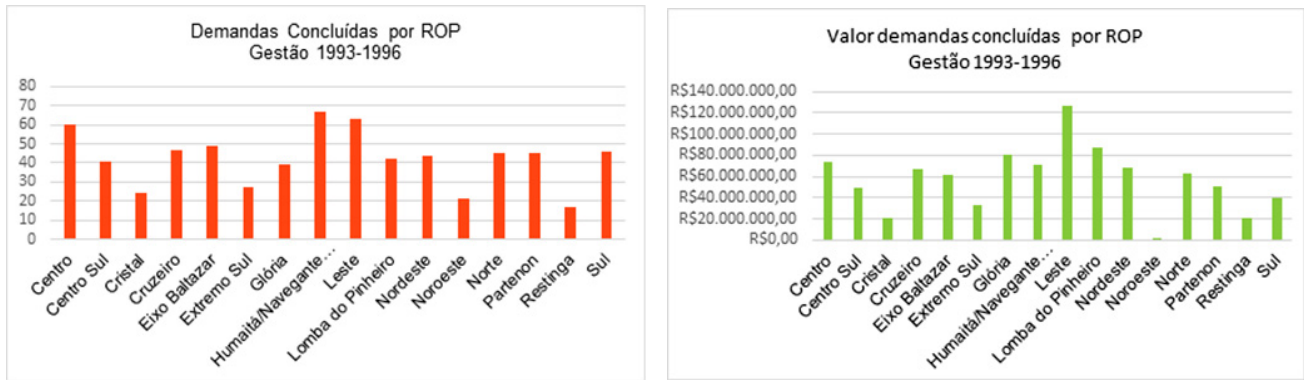

Fonte: Gerência de Democracia Participativa Local - Prefeitura Municipal de Porto, em 2018. 
Figura 3 - Demandas concluídas na gestão 1997-2000 - AP
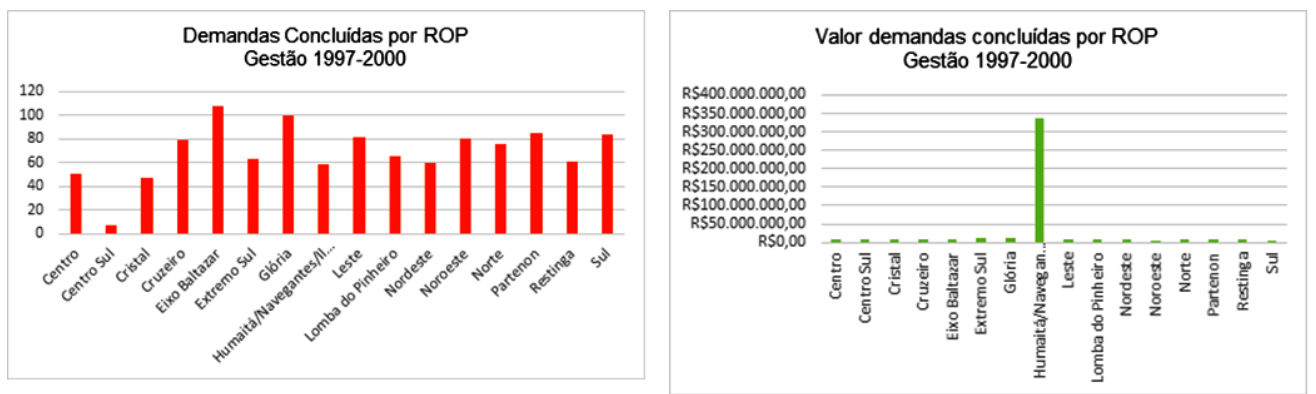

Fonte: Gerência de Democracia Participativa Local - Prefeitura Municipal de Porto, em 2018.

OBS: O valor discrepante de $\mathrm{R} \$ 330.358 .769,00$, na ROP Humaitá/Navegantes/llhas, refere-se à conclusão do Conduto Forçado da avenida Polônia/Bacia de Amortecimento.

Figura 4 - Demandas concluídas na gestão 2001-2004 - AP
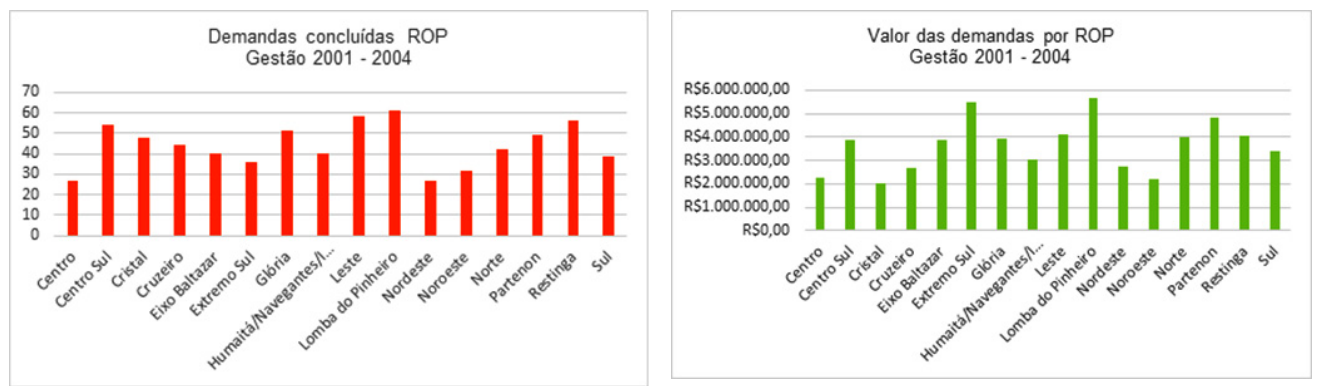

Fonte: Gerência de Democracia Participativa Local - Prefeitura Municipal de Porto, em 2018.

Nesse último período de governo da coalizão de esquerda polarizada pelo Partido dos Trabalhadores (2001-2004), apresentado na Figura 4, as demandas concluídas seguem concentradas nas grandes e tradicionais áreas periféricas, a saber, nas regiões Lomba do Pinheiro, Partenon e Restinga, mas, também em regiões pericentrais, como a Leste, Glória e Centro-Sul; enquanto os investimentos se concentram no Extremo-Sul e também na Lomba do Pinheiro e Partenon, regiões que avançaram na experiência participativa, a partir de uma tradição associativa e com graves problemas de infraestrutura e serviços urbanos. 
Entre 2005-2008 (Figura 5), tem-se o primeiro período de continuidade do OP sem um governo socializante. No entanto, tratava-se de um governo eleito comprometido com a manutenção do OP e, em alguma medida, o manteve. As informações na Figura 5 demonstram uma diminuição de conclusão de demandas no período, assim como também de recursos investidos. Cristal, Glória, Cruzeiro e Restinga aparecem como regiões com mais demandas concluídas, em quantidade menor de $1 / 3$ àquelas em posição semelhante nos períodos anteriores, e com uma inflexão novamente para regiões pericentrais, com exceção da Restinga. Os valores investidos também têm forte queda, cerca de $50 \%$ nas regiões agora com os maiores investimentos, em relação aos períodos anteriores, com concentração no sul da cidade, nas regiões Sul, Restinga ${ }^{6}$ e Extremo-Sul.

Existe uma continuidade do governo anterior e da mesma política de manutenção do OP, no entanto as informações na Figura 6 apontam para uma estabilização na conclusão de demandas e um volume de investimento que atinge valores maiores que nos períodos de governos que implantaram o OP. Também se encontra uma distribuição mais equânime

Figura 5 - Demandas concluídas na gestão 2005-2008 - Governança Solidária Local
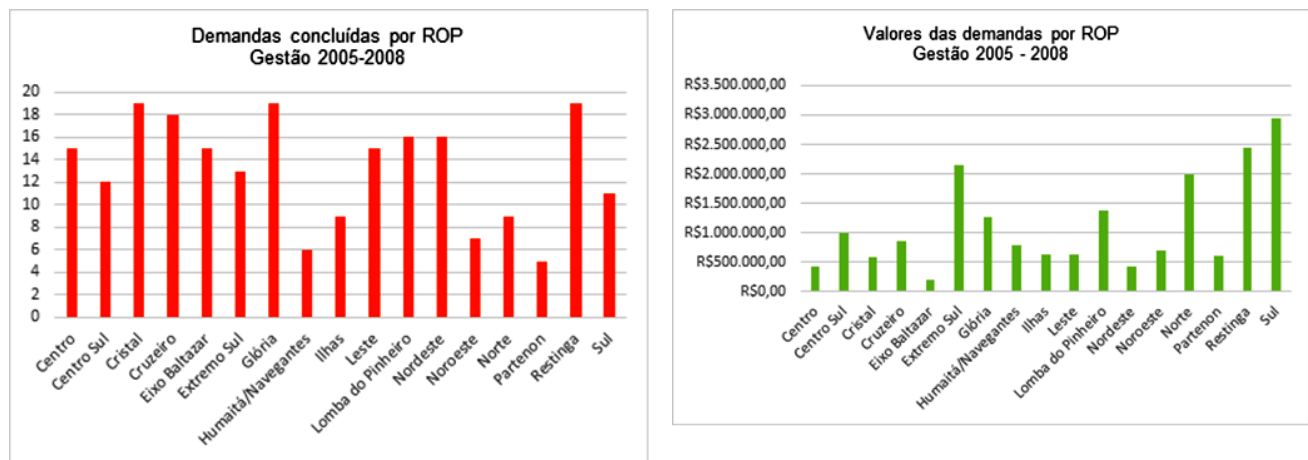

Fonte: Gerência de Democracia Participativa Local - Prefeitura Municipal de Porto, em 2018.

Figura 6 - Demandas concluídas na gestão 2009-2012 - Governança Solidária Local
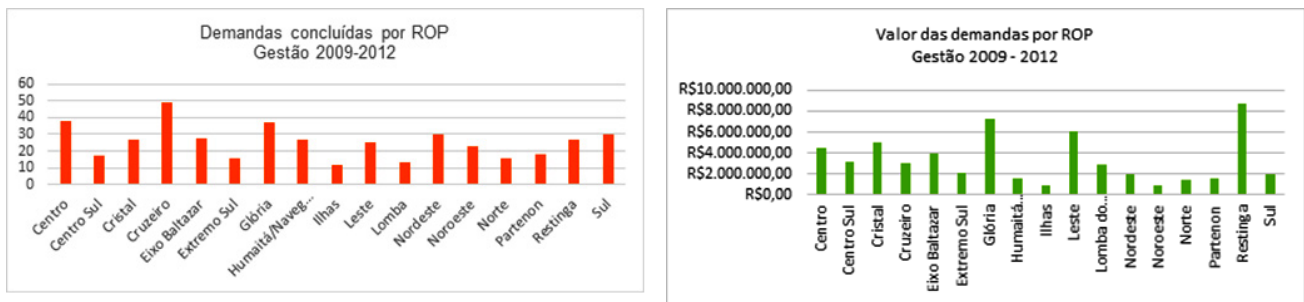

Fonte: Gerência de Democracia Participativa Local - Prefeitura Municipal de Porto, em 2018. 
de conclusão de demandas por região e mesmo de recursos, com exceção das regiões Restinga, Glória e Leste, com maiores investimentos, em especial Restinga e Glória.

Nesse último período de existência (2013-2016) do OP, tem-se uma queda vertiginosa na conclusão de demandas e nos valores investidos. 0 esvaziamento paulatino da experiência participativa de definição dos recursos pela população fez com que o OP chegasse ao seu final, embora ele tenha se mantido institucionalmente em atividade. No entanto, relatos de participantes já apontam para o fim do próprio funcionamento.

$\mathrm{Na}$ análise da Figura 8, observa-se um aumento de $57 \%$ no atendimento das demandas entre o primeiro governo (1989-1993), responsável pela implantação do OP, e o segundo (1993-1996), depois se dá uma queda no atendimento das demandas de cerca de $50 \%$

Figura 7 - Demandas concluídas na gestão 2013-2016 - Governança Solidária Local
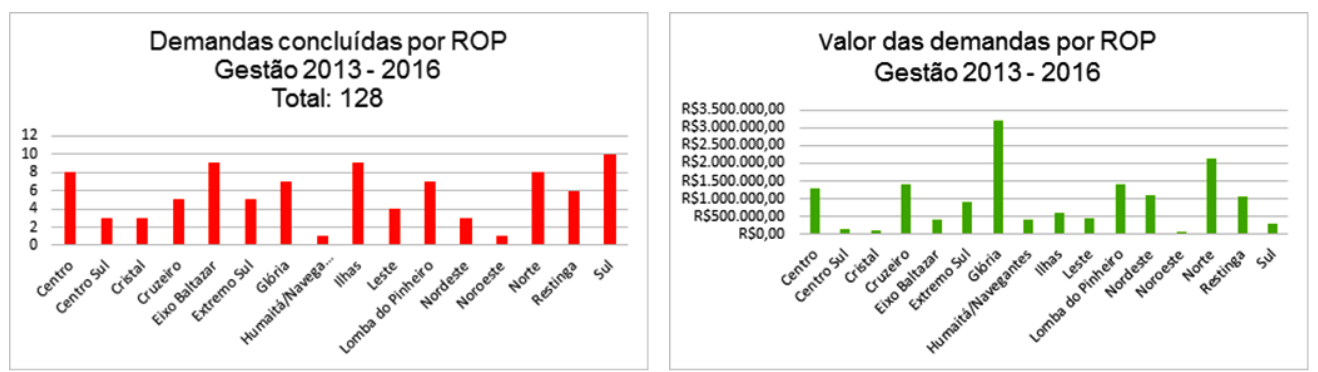

Fonte: Gerência de Democracia Participativa Local - Prefeitura Municipal de Porto, em 2018.

Figura 8 - Demandas concluídas 1989-2016

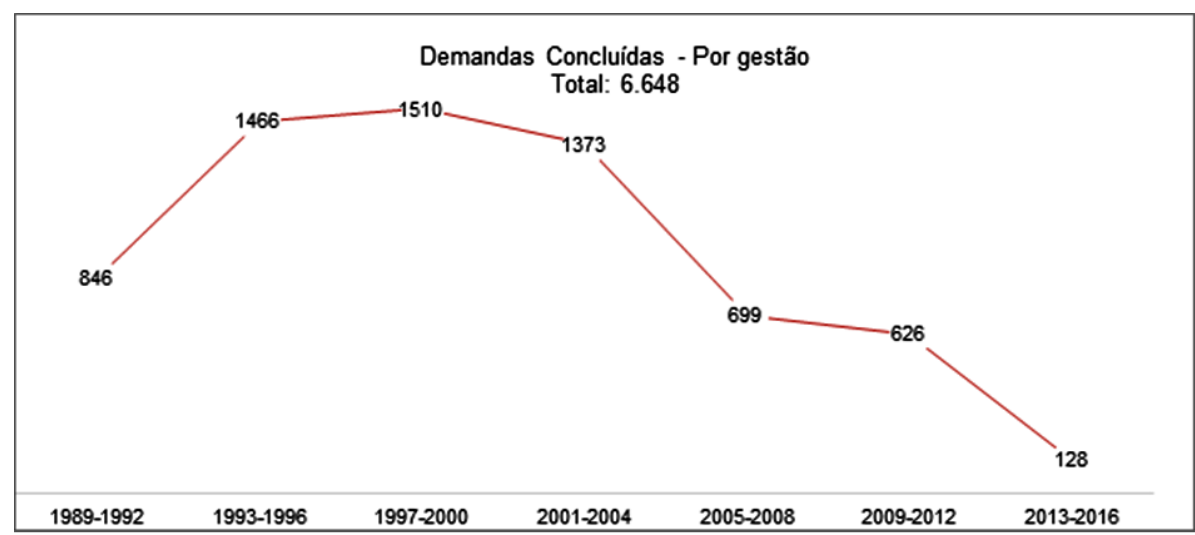

Fonte: Gerência de Democracia Participativa Local - Prefeitura Municipal de Porto Alegre, em 2018. 
entre o último governo da AP (2001-2004), tendo à frente o Partido dos Trabalhadores, e o primeiro de Governança Solidária Local (20052008), de composição centrista. Esses níveis se mantêm no período seguinte (2009-2012), para diminuírem em quase $80 \%$ no último período (2013-2016). Da média do período de ápice de atendimento das demandas (19932004), cerca de 1.500 , chega-se à diminuição de aproximadamente $90 \%$ no atendimento de demandas, no último período de existência do OP (2013-2016). Ou seja, se a legitimidade do OP estava fundada na experiência de um instrumento de democracia participativa que permitia, aos participantes, verem suas decisões realizadas, tal diminuição teria, necessariamente, como efeito a perda de relevância e legitimidade, tornando inevitável seu fim.

A Figura 9 mostra a ascensão e queda do OP, também em relação aos investimentos. O movimento de diminuição de investimento foi similar ao de atendimento de demandas, a partir de um ápice no período 1993-1996. Todavia, houve uma grande diminuição de investimento no período dos governos da AP, entre 1993-1996 e 1997-2000, de mais de 50\%, proporcionalmente semelhante à diminuição encontrada de 2001-2004 a 2005-2008, mas nada parecido com o quase desaparecimento de investimentos constatado de 2005-2008 para 2009-2013, de quase 90\%! Provavelmente no período 1993-1996 houve o ingresso de altos valores de investimentos internacionais, explicando a grande queda para o período seguinte (1997-2000). Em termos gerais, fora o salto abismal de investimentos de 1989-1992 para 1993-1996, de cerca de $\mathrm{R} \$ 96$ milhões para $\mathrm{R} \$ 1$ bilhão e 900 milhões, a curva foi sempre descendente, porém com acelerações. Se excetuarmos o período 1993-1996, a curva descendente acelera-se a partir da saída dos governos da AP. Se há decréscimo

Figura 9 - Investimentos realizados 1989-2016

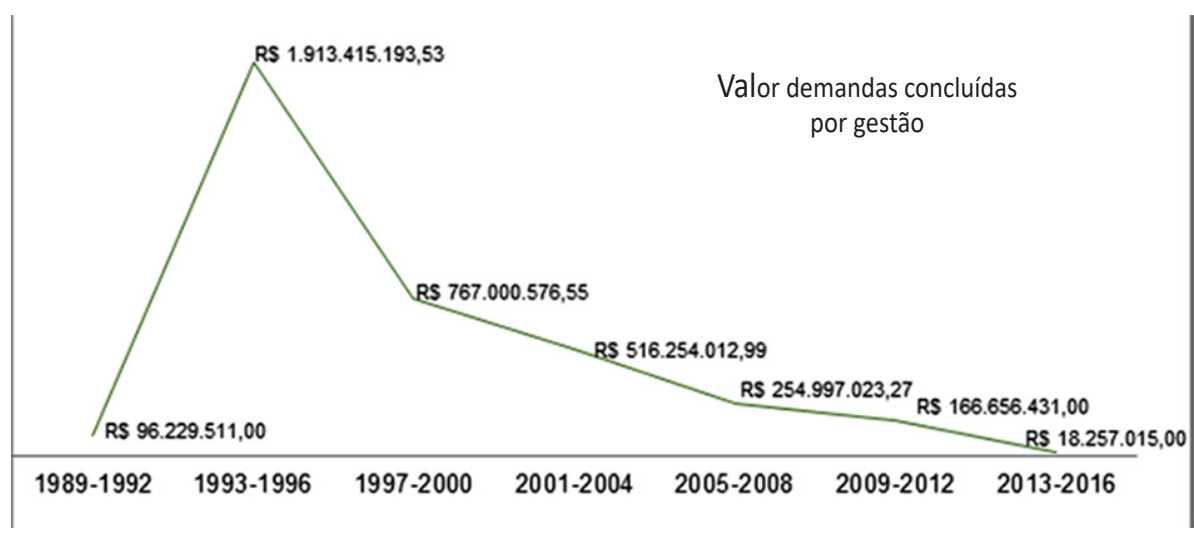

Fonte: Gerência de Democracia Participativa Local - Prefeitura Municipal de Porto Alegre, em 2018. OBS: O poder público não dispõe de dados completos referentes aos valores de todas as demandas da primeira gestão (1989-1992). 
de investimentos nos períodos seguintes de 1997-2000 a 2001-2004, de cerca de 30\%; de 2001-2004 a 2005-2008, a diminuição fica em aproximadamente 50\%; de 2005-2008 a 20092012 a diminuição desacelera para 35\%; chegando ao ápice de 2009-2012 a 2013-2016 de quase de $90 \%$. Com pouco mais de uma centena de demandas atendidas e pouco mais de $\mathrm{R} \$$ 18 milhões de investimentos, cerca de $80 \%$ a menos que no primeiro período (1989-1992), quando as administrações ainda sucumbiam sobre os efeitos da chamada década perdida (1980), o processo de esvaziamento do OP já estava dado antes mesmo da decisão de 2017 de não atender às demandas.

Em relação à gestão atual (2017-2020), a situação colocada pelo governo aponta para um atendimento de demandas e valor investido muito abaixo das demandas acumuladas. Logo nas primeiras reuniões do COP, o governo apresentou as dificuldades financeiras que a administração atravessava e anunciou a não realização de demandas no ano de 2017. Para os anos seguintes, além dos cortes realizados nas demandas atrasadas pelos técnicos da prefeitura, propôs-se, aos conselheiros, que também enxugassem demandas junto aos delegados. Em janeiro de 2017 havia 2.369 demandas atrasadas, das quais 672 foram canceladas, entre elas 155 demandas das temáticas e 517 demandas das regiões. Permaneceram 1.697 demandas (364 das temáticas e 1.333 das regiões). ${ }^{7}$ As demandas resultantes integraram o Plano de Investimento e Serviços - 2017/2018. ${ }^{8}$

Após a etapa de elaboração do Plano de Investimentos e Serviços, a equipe técnica do OP efetuou, com as secretarias, nova seleção e incluiu apenas 59 demandas na Lei Orçamentária Anual - LOA 2019 e o valor total correspondente a $\mathrm{R} \$ 274.606 .000,00$. Entre as demandas, encontram-se aquelas apresentadas pelo governo em anos anteriores e resgatadas em 2019. As demandas do governo perfazem o valor total de $\mathrm{R} \$ 230.811 .971,00$, conforme Tabela 1. Portanto, o valor proposto para investimento, em 2019, nas demandas apresentadas pelas comunidades é de apenas $\mathrm{R} \$ 43.794 .020,00$. Ou seja, do montante proposto para o Orçamento Participativo, apenas $15 \%$ será destinado à execução de demandas das comunidades em 2019. Ainda, as demandas para moradia foram reduzidas apenas às demandas para as cooperativas como complementação das necessidades para acessar o PMCMV - Entidades. A única demanda certa em relação à moradia é a disponibilização de mil unidades de casas de emergência, aquelas destinadas para casos de sinistro nas comunidades carentes.

Por ocasião da apresentação das demandas que entraram na LOA, o Conselho do OP refutou a proposta. Pela primeira vez o Projeto da LOA foi para a Câmara Municipal de Vereadores de Porto Alegre sem a aprovação do COP, ${ }^{9}$ desde 1989.

Apesar de a população ter sido afastada do exercício histórico de se reunir para debater e propor demandas no ano de 2017, a disposição de milhares de participantes para discutir a situação do Orçamento Participativo na rodada de assembleias no ano de 2018 não foi arrefecida. Ao longo do processo, 5.435 pessoas participaram das assembleias nas regiões, distribuídas conforme Figura 10.

Com base na perspectiva de atendimento de demandas (Tilly, 2013), as informações demostram o processo de desdemocratização a partir do GSL de 2009-2013, com o esvaziamento quase absoluto do atendimento de 
Tabela 1 - Demandas do Governo no Orçamento Participativo - LOA 2019

\begin{tabular}{l|c}
\multicolumn{1}{c|}{ Demandas do governo } & Valor em R\$ \\
\hline Obra de Arte (Trincheira) na 3o Perimetral (Ceará x Farrapos) & $2.687 .531,00$ \\
\hline Obra de Arte (Trincheira) na 3o Perimetral (Carlos Gomes x Anita Garibaldi) & $312.839,00$ \\
\hline Obra de Arte (Viaduto) 3 Perimetral (Carlos Gomes x Plínio Brasil Milano) & $42.724 .996,00$ \\
\hline Obra de Arte (Trincheira) na 3o Perimetral (Dom Pedro II x Cristóvão Colombo) & $9.259 .064,00$ \\
\hline Projeto Orla do Guaíba & $28.000 .000,00$ \\
\hline Obras da Copa 2014 - Implantação da avenida Tronco & $79.597 .239,00$ \\
\hline Duplicação da avenida Voluntários da Pátria & $31.758 .762,00$ \\
\hline Obras da Copa 2014 - prolongamento da avenida Severo Dullius & $26.488 .080,00$ \\
\hline BRT avenida João Pessoa & $4.983 .460,00$ \\
\hline Ciclovias & $5.000 .000,00$ \\
\hline Total & $230.811 .971,00$ \\
\hline
\end{tabular}

Fonte: Lei Orçamentária Anual 2019 - Porto Alegre, outubro de $2018 .^{10}$

Figura 10 - Número de participantes nas assembleias regionais - 2018

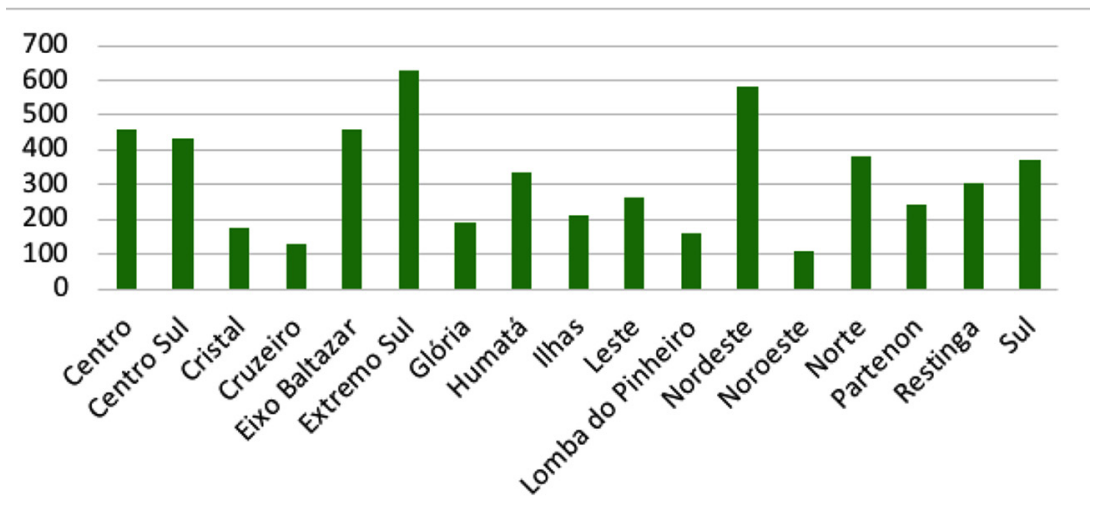

Fonte: Gerência de Democracia Participativa Local - Prefeitura Municipal de Porto, em 2018. 
demandas e investimentos, tendo como ápice a posição oficial em 2017, período tratado como de democracia ultraliberal, de não atendimento de demandas. Dada a posição política desse governo (2017-2020), sugere-se que tenha ocorrido algum nível de organização e pressão política popular que o levou a retomar as atividades do OP em 2018, mantendo, todavia, o quase total esvaziamento de atendimento de demandas e investimentos. As informações ainda recentes e dependentes de maiores análise permitem a suposição da existência de uma potência popular ainda em curso, quiçá a mesma que deu origem ao OP. É possível supor até mesmo que tenha havido algum fortalecimento desses processos cognitivos da experiência de democracia participativa, em alguma medida em tensão com o processo de desdemocratização e mesmo incidindo no movimento pendular da história da democracia brasileira. As informações na Figura 10 sobre o número de participantes, por mais que possa haver manipulação no sentido de inflar dados, a fim de atribuir uma legitimidade ao processo agora dirigido por um governo de direita ultraliberal, demonstram resiliência popular na manutenção do OP, tanto quanto a posição dos conselheiros em não aprovar a LOA, retirando, assim, a legitimidade popular que a concordância pelo COP daria para aprovação da Lei Orçamentária Anual na Câmara Municipal. Pode-se sugerir que tal inflexão no pêndulo (Avritzer, 2018) no sentido da desdemocratização (Rancière, 1996, 2014; Tilly, 2013) traz à tona a necessidade de um projeto de democracia radical fundado no dissenso à la Mouffe (1999; 2003) para empurrar o pêndulo para o lado da maxD (Menser, 2005).

\section{Conclusões}

A análise realizada a partir do comportamento da democracia como resposta do governo às demandas da população, conforme Tilly (2013), apontou para declínio geral desde a Administração Popular até a gestão atual, passando pela Governança Solidária Local em que se acelera. Observamos que, nos primeiros estágios do Orçamento Participativo, a prioridade era articular a democracia com as necessidades mais urgentes da população. Pequenas obras, porém, importantes, contribuíram para qualificar os espaços dos pobres na cidade, integrando-os à cidade formal, possibilitando, inclusive, fortalecer "dinâmicas de enraizamento" (Marzulo, 2005, p. 118), de afirmação de identidade com o local de morada e segurança em permanecer nele.

As obras estruturantes definidas nas temáticas, sobretudo na temática Organização da Cidade, Desenvolvimento Urbano-Ambiental, e financiadas por organismos internacionais ao longo da Administração Popular, mantiveram diálogo com outras demandas do OP, ou seja, foram complementares. Mesmo a implantação da III Perimetral se converteu numa via importante para o deslocamento de milhares de trabalhadores que cruzavam a cidade.

No decorrer da administração da Governança Solidária Local (GSL), ocorreu o melhor cenário para investimentos nas demandas do OP. A disponibilidade de recursos financeiros do Governo Federal, o arcabouço jurídico oriundo do Estatuto da Cidade e a disponibilização de programas, como Urbanização de Assentamentos Precários, que possibilitava 
intervenções diversas nas áreas carentes, poderiam ter atendido a um número maior de demandas. No entanto, isso não ocorreu.

A prioridade no governo da GSL foi em obras do próprio governo, considerando outros critérios e não as demandas das comunidades no OP. Lembrando que foi neste governo que foram elaborados todos os projetos de mobilidade e requalificação de entorno de estádios para a realização da Copa do Mundo Fifa 2014; ao invés de atender a demandas do $\mathrm{OP}$, comunidades inteiras foram removidas de seus locais de moradia. Ainda, no caso da duplicação da avenida Tronco, moradores removidos perderam o acesso aos equipamentos públicos e a todas as pequenas obras resultantes das demandas realizadas ao longo da história do OP.

Na gestão do atual governo Marchezan Júnior, o cenário é o pior da história do OP. Além do baixo número de demandas inseridas na LOA 2019, as dificuldades enfrentadas nacionalmente em relação ao programa Minha Casa Minha Vida - Entidades, particularmente, e em relação à nova lei para regularização fundiária, fazem com que as chances de execução das demandas definidas para 2019 caiam mais ainda. Ou seja, com exceção das casas de emergência, todas as demandas de moradia dependem de fatores externos fragilizados na sua origem.

Do ponto de vista geral, das instituições participativas, Porto Alegre ainda mantém amplo espectro de espaços para exercício da democracia. Considerando a visão de Menser (2005) quando propõe a maxD e minD, podemos afirmar que Porto Alegre esteve no maxD durante os primeiros anos dos governos da Administração Popular, deslocando-se, ainda, para o minD. Se olharmos para o movimento pendular da democracia, através das lentes de Avritzer, e considerando a execução de demandas como resposta do governo ao povo (Tilly, 2013), o pêndulo desloca-se para a desdemocratização.

Ocorre, porém, que o principal componente do $\mathrm{OP}$, que é a participação popular, não está apagado. 0 fato de ter ocorrido pela primeira vez a entrega do Projeto da LOA sem a aprovação do COP significa que a prática do consenso entre os representantes das comunidades e o governo está apresentando sinais de fragilidade. Considerando, ainda, que um dos elementos da crise da democracia está na relação entre representantes e representados, a crise atual do OP pode ser superada a partir da diminuição dos consensos entre conselheiros e governo e de mais diálogo e construção com as bases. Levando em conta que o número de participantes nas assembleias regionais em 2018 compõe um grupo qualificado de participantes, apesar de diminuto, se comparado com os áureos tempos de assembleias lotadas, encontram-se aí alternativas à crise do OP a partir das próprias bases. "Por que o prefeito Marchezan Júnior não vem conversar conosco? Nós sabemos como trabalhar em crise. Já fizemos isso no passado podemos fazer agora, também" (participante de assembleia). E sabem. Talvez esteja na crise atual do OP uma oportunidade para revitalizar e radicalizar a democracia em Porto Alegre. 


\section{[I] https://orcid.org/0000-0002-6848-9012}

Conselho Nacional de Desenvolvimento Científico e Tecnológico, Institutos Nacionais de Ciência e Tecnologia, Programa de Pesquisa da Rede Observatório das Metrópoles. Porto Alegre, RS/Brasil. lupiaf@gmail.com

\section{[II] https://orcid.org/0000-0001-5965-4891}

Universidade Federal do Rio Grande do Sul, Faculdade de Arquitetura, Departamento de Urbanismo, Programa de Pós Graduação em Planejamento Urbano e Regional. Faculdade de Ciências Econômicas, Curso de Planejamento e Gestão para o Desenvolvimento Rural, Programa de Pós-Graduação em Desenvolvimento Rural. Porto Alegre, RS/Brasil.

eber.marzulo@ufrgs.br

\section{Notas}

(1) Disponível em: http://www2.camara.leg.br/legin/fed/decret/2017/decreto-9076-7-junho-2017785030-publicacaooriginal-152979-pe.html.

(2) "Maximal democracy considers the entire economic and sociocultural plane to be a proper field for democratic desires and practices. As such, the organization of everyday life in schools, recreation, the household, the workplace, religion, and the family unit are not distinct spheres to be protected by proper subjects for transformation. This democratization of society requires the (re)construction of a set of political and economic institutions that further the capacities and knowledges required for self-rule. Again, maxD is not a matter of spelling out individual rights. It is, rather, about the production of a set of collective capacities."

(3) Atualizado pelos autores a partir de Gomes (2011).

(4) Disponível em: http://www2.portoalegre.rs.gov.br/op/default.php?p_secao=5.

(5) Os valores correspondentes às demandas realizadas no primeiro período não eram registrados e identificados como obras do OP. Por isso os valores apresentados na Figura 1 não correspondem à totalidade das demandas concluídas no período. No entanto, entendemos importante apresentar os dados disponíveis.

(6) A Restinga é um bairro popular produzido no final dos anos de 1960-1970 pela remoção de favelas de área central e se localiza no sul da cidade.

(7) Apresentação realizada na Assembleia do OP, em 25 de julho de 2018.

(8) Disponível em: http://Iproweb.procempa.com.br/pmpa/prefpoa/observatorio/usu_doc/ compacto_do_plano_de_investimentos_e_servicos_2018.pdf

(9) Notas da reunião do COP.

(10) Disponível em: http://www2.portoalegre.rs.gov.br/smpeo/default.php?reg=14\&p_secao=56. 


\section{Referências}

AVRITZER, L. (2018). O pêndulo da democracia no Brasil. Uma análise da crise 2013-2018. Novos Estudos. São Paulo, v. 37, n. 2, pp. 273-289.

BOBBIO, N. (2000). Liberalismo e democracia: a filosofia política e as lições dos clássicos. São Paulo, Brasiliense.

BOBBIO, N.; BOVERO, M. (orgs.) (2000). Teoria geral da politica: a filosofia política e as lições dos clássicos. Rio de Janeiro, Campus.

BRASIL (2001). Lei n. 10.257, de 10 de julho. Regulamenta os arts. 182 e 183 da Constituição Federal, estabelece diretrizes gerais da política urbana e dá outras providências.

(2008). Estatuto da Cidade. Brasília.

FEDOZZI, L. (2000). O poder da aldeia. Gênese e história do Orçamento Participativo de Porto Alegre. Porto Alegre, Tomo Editorial.

FERNANDES, E. (2011). Regularização de assentamentos informais na América Latina. Massachusetts, Lincoln Institute of Land Policy.

FILOMENA, C. L. (2015). PT e administração popular: democracia interna, conflito e participação (19892004). Trabalho de conclusão de Curso. Porto Alegre, Universidade Federal do Rio Grande do Sul.

GENRO, T. (1997). Orçamento participativo. A experiência de Porto Alegre. São Paulo, Fundação Perseu Abramo.

GOMES, A. Q. (2011). Conselhos Municipais em Porto Alegre - 1937/2008: Quem participa? Tese de doutorado. Porto Alegre, Universidade Federal do Rio Grande do Sul.

HARVEY, D. (2004). O novo imperialismo. São Paulo, Loyola.

JAMESON, F. (2011). Representing Capital. A Commentary on Volume One. Londres, Verso.

MARZULO, E.; MARX, V. (2013). Poder local y crisis global: cambios en la trayectoria de Porto Alegre. Revista Cidob Afers Internacionais, n. 104, Nueva época, Dicimbre.

MARZULO, E. P. (2005). Espaço dos pobres. Identidade social e territorialidade na modernidade tardia. Tese de doutorado. Rio de Janeiro, Universidade Federal do Rio de Janeiro.

MENSER, M. (2005). The Global social Forum Movement. Porto Alegre's 'Participatory Budget', and the Maximization of Democracy. Situations, v. 1, n. 1, pp. 87-109.

MOUFFE, C. (1999). El retorno de lo político. Comunidad, ciudadania, pluralismo, democracia radical. Barcelona, Paidós.

(2003). Democracia, cidadania e a questão do pluralismo. Política \& Sociedade. Florianópolis, n. 3 , pp.11-26. Disponívelem:https://periodicos.ufsc.br/index.php/politica/article/viewFile/2015/1763. Acesso em: 13 set 2018.

NAHRA, C. M. L. (2005). Os Conselhos Municipais Gestores de Políticas Públicas em Porto Alegre. Um panorama. Porto Alegre, Prefeitura Municipal de Porto Alegre.

NUÑEZ, T. (2010). Participação e mudança política. A experiência do Orçamento Participativo em Porto Alegre. Dissertação de mestrado. Porto Alegre, Universidade Federal do Rio Grande do Sul. 
ONG SOLIDARIEDADE (2003). Caminhando para um mundo novo. Orçamento Participativo de Porto Alegre visto pela comunidade. Petrópolis, Vozes.

PONT, R. (2000). “Democracia representativa e democracia participativa”. In: BECKER, A. J. (org.). A cidade reinventa a democracia. Contribuições do Seminário Internacional sobre Democracia Participativa. Porto Alegre, Prefeitura Municipal de Porto Alegre.

PORTO ALEGRE (2018). Orçamento Participativo. Regimento Interno. Critérios gerais, técnicos e regionais 2018/2019. Porto Alegre, Prefeitura de Porto Alegre.

RANCIÈRE, J. (1996). “O dissenso". In: NOVAES, A. (org.). A crise da razão. São Paulo, Companhia das Letras.

(2014). O ódio à democracia. São Paulo, Boitempo.

SANHUDO, A. V. (1961). Porto Alegre. Crônicas da minha cidade. Porto Alegre, Sulina.

SANTOS JÚNIOR, O.; NASCIMENTO, C.; FERREIRA, R. F. C. (2007). O Sistema Nacional de Desenvolvimento Urbano: avanços e limites para a descentralização dos canais de participação. Santa Maria. Disponível em: http://iplan.santamaria.rs.gov.br/uploads/projeto/17568/sistemaNacionalDesenvolvimentoUrbano. pdf. Acesso em: 10 jul 2018.

SAULE, N.; UZZO, K. (2009). La trayectoria de la reforma urbana en Brasil. In: DPH, 2009. Disponível em: http://base.d-p-h.info/es/fiches/dph/fiche-dph-8544.html. Acesso em: jul 2018.

SINTOMER, Y.; HERZBERG, C.; RÖCKE, A. (2012). Modelos transnacionais de participação cidadã: o caso do Orçamento Participativo. Sociologias. Porto Alegre, ano 14, n. 30, pp. 70-116.

TILLY, C. (2013). Democracia. Petrópolis, Vozes.

VAINER, C. (2005). "Planejamento urbano democrático no Brasil contemporâneo". In: ERBA, D. A. (org.). Cadastro multifinalitário como instrumento da política fiscal e urbana. Rio de Janeiro, Ministério das Cidades. 
